\title{
30 anos de Ombudsman ou mais: os primórdios da crítica dos meios de comunicação na Paraíba
}

\author{
Sandra MOURA ${ }^{1}$ \\ Marcella MACHADO ${ }^{2}$
}

\begin{abstract}
Resumo:
O jornalismo na Paraíba registra, desde o início da década de 1980, um ensaio de crítica dos meios de comunicação e do que, posteriormente, seria chamado de ombudsman. No jornal $O$ Norte, por meio de um boletim de circulação interna, o jornalista Wills Leal fazia suas análises. Em 1989, no semanário $A$ Tribuna, Fernando Moura e Alarico Correia Neto estreavam a coluna Fidibeque. A partir de 1991, o jornal Correio da Paraíba firmou convênio com a Universidade Federal da Paraíba (UFPB) para que os professores Carmélio Reynaldo e Alarico Correia Neto exercessem papel de críticos em uma coluna chamada de (Re)Visão. Mais adiante, em 1995, com a saída dos dois docentes, o jornal manteve o formato da coluna de ombudsman, dessa vez com o jornalista Rubens Nóbrega, que já havia editado o periódico. Essas vivências da crítica cotidiana dos jornais paraibanos serão relatadas e analisadas neste artigo. Examinaremos, entre outros aspectos, o contexto em que essas experiências ocorreram, as relações estabelecidas com a redação e os leitores.
\end{abstract}

Palavras-chave: Ombudsman. Crítica de mídia. Jornalismo paraibano.

\section{0 years of Ombudsman or more: the beginnings of media criticism in Paraíba}

\begin{abstract}
:
Journalism in Paraíba has, since the early 1980s, recorded a critical essay on the media and what would later be called an ombudsman. In the newspaper $O$ Norte, through an internal circulation newsletter, journalist Wills Leal made his analysis. In 1989, in the weekly A Tribuna, Fernando Moura and Alarico Correia Neto debuted the column Fidibeque. From 1991, the newspaper Correio da Paraíba signed an agreement with the Federal University of Paraíba (UFPB) for professors Carmélio Reynaldo and Alarico Correia Neto to play this role of critics in a column called (Re)Visão. Later, in 1995, with the departure of the two professors, the newspaper retained the format of the ombudsman column, this time with the journalist Rubens Nóbrega, who had already edited the journal. These experiences of the daily criticism of Paraíba newspapers will be reported and analyzed in this article. We will examine, among other things, the context in which these experiences took place, the relationships established with the newsroom and the readers.
\end{abstract}

Keywords Ombudsman. Media criticismo. Paraiban journalism.

\footnotetext{
' Doutora em Comunicação e Semiótica pela Pontifícia Universidade Católica de São Paulo - PUC-SP e Professora do Mestrado Profissional em Jornalismo da Universidade Federal da Paraíba - UFPB. E-mail: sandra.moura@academico.ufpb.br.
}

2 Mestranda em Jornalismo no Mestrado Profissional em Jornalismo da Universidade Federal da Paraíba UFPB.E-mail: marcellamachadopb@gmail.com. 


\title{
30 años de Ombudsman o más: los primórdios de la crítica de los medios de comunicación en Paraíba
}

\begin{abstract}
Resumen:
El periodismo en Paraíba graba, desde el principio de la década de 1980, un ensayo de la crítica de los medios de comunicación, y que, después, llamarían de Ombudsman. En el periódico $O$ Norte, a través de un boletín informativo de circulación interna, el periodista Wills Leal lo hizo sus análisis. En el año de 1989, en el semanario A Tribuna, Fernando Moura e Alarico Correia Neto debutaron la columna de opinión Fidibeque. Desde 1991, el periódico Correio da Paraíba firmó acuerdo con la Universidade Federal da Paraíba (UFPB) para que los profesores Carmélio Reynaldo e Alarico Correia Neto jueguen el papel de críticos en la columna de opinión llamada (Re)Visão. Adelante, en el año de 1995, por la partida de los dos profesores, el periódico mantuvo el formato de Ombudsman, esta vez con el periodista Rubens Nóbrega, que ya cambiara el periódico. Estas vivencias de crítica en el cotidiano de los periódicos paraibanos son descritos y analizados en este trabajo. Examinamos, entre otros aspectos, el contexto en que estas experiencias tuvieron lugar, las relaciones establecidas con la redacción y los lectores.
\end{abstract}

Palabras clave: Ombudsman. Crítica de los médios. Periodismo paraibano.

\section{Introdução}

Em 2015, Juliana de Amorim Rosas defendeu dissertação intitulada Os cães ladram, a caravana passa e apenas ao leitor se deve reverência: o pioneirismo regional do ombudsman paraibano entre críticas, estratégias e conflito de Ethos, no qual apresentava a trajetória dos três ombudsnatos do jornal Correio da Paraíba. Segundo a pesquisadora, a experiência paraibana foi a segunda a surgir no Brasil, dois anos após a Folha de S. Paulo, e considerada a pioneira nas regiões Norte/Nordeste, dois anos antes do cearense O Povo. Neste artigo, ampliamos o estudo de Rosas (2015), mostrando como a crítica dos meios de comunicação no estado já vinha sendo ensaiada por outros periódicos e jornalistas locais, não necessariamente na função de ombudsman, mas com algumas das características a este profissional atribuídas, posteriormente.

$\mathrm{Na}$ Paraíba, há registros de duas experiências de crítica de mídia que antecederam a iniciativa da figura do ombudsman do Correio da Paraíba. A primeira delas trata-se dos boletins de avaliação interna do jornal $O$ Norte, datado do início da década de 1980. As críticas eram elaboradas pelo jornalista Wills Leal, mas não eram publicadas. A segunda ocorreu no semanário A Tribuna, em 1989, com a coluna Fidibeque, escrita pelos jornalistas Alarico Correia Neto e Fernando Moura.

Giangrande e Figueiredo (1997, p. 26) definem o ombudsman "como um instrumento a ser utilizado para despertar a cidadania, não apenas desenvolvendo a noção dos direitos, mas também transformando as pessoas de sujeitos a protagonistas". Costa (2006) demarca as atividades do "representante dos leitores" como a elaboração 
de uma crítica interna e externa, distribuída entre os profissionais da redação, com tópicos nos quais discutia-se questões sobre a acuidade da informação, erros, vícios, discriminações, gramática, entre outros aspectos.

Ler as edições do jornal como um leitor comum e como um profissional do jornalismo eram as habilidades desempenhadas pelos ouvidores. Embora visto como um defensor do público, o ombudsman não assumia o papel de um advogado que aceita uma defesa mesmo consciente do erro do cliente (COSTA, 2006). De acordo com Mendes, (2002, p. 17-18), como representante dos leitores, o ombudsman tem o compromisso de respeitar a opinião do público, "o que não quer dizer que ele vá sempre concordar com a opinião dos leitores e defender o ponto de vista deles. $\mathrm{O}$ 'representante do leitor' não é passivo e sem opinião".

As formas de denominar essa função e esse profissional variam. Na Espanha é visto como o "defensor del lector", na França é o "médiateur", já em Portugal é o "provedor dos leitores, dos ouvintes e dos telespectadores" (CHRISTOFOLETTI, 2010). O ombudsman na mídia, de acordo com Mesquita (1998), pode ter entre as suas atuações as funções crítica e simbólica, mediadora, corretiva, persuasiva, pedagógica, dissuasiva e cívica.

São algumas dessas características que veremos nos relatos de Evandro da Nóbrega, ${ }^{3}$ sobre a época do trabalho de Wills Leal, ${ }^{4}$ em $O$ Norte, dos jornalistas Fernando Moura ${ }^{5}$ e Alarico Correia Neto, ${ }^{6}$ no semanário A Tribuna, assim como de Carmélio Reynaldo, ${ }^{7}$ Rubens Nóbrega ${ }^{8}$ e do próprio Alarico Correia Neto, no jornal Correio da Paraíba. Os depoimentos desses profissionais foram coletados entre 2018 e 2019.

Em $O$ Norte, Wills Leal analisava das manchetes aos anúncios publicados no periódico e nos demais jornais locais (NÓBREGA, E., 2019). Posteriormente, observamos a experiência de crítica de mídia, implementada no jornal semanal $A$

${ }^{3}$ NÓBREGA, Evandro. Entrevista. [out. 2019]. Entrevistadora: Marcella Machado. João Pessoa. E-mail. ${ }^{4}$ Em 2019, na impossibilidade de ouvir o jornalista Wills Leal, de 83 anos, que se encontrava com a saúde debilitada, entrevistamos o jornalista Evandro da Nóbrega, que acompanhou, na condição de editor-geral do periódico, a atividade do colega que fazia a crítica do jornal $O$ Norte. Wills Leal morreu em 7 de maio de 2020, em decorrência de uma parada cardiorrespiratória.

${ }^{5}$ MOURA, Fernando. Entrevista. [jul. 2018]. Entrevistadora: Marcella Machado. João Pessoa. 1 arquivo .mp3 (10 min.).

6 CORREIA NETO, Alarico. Entrevista. [jun. 2018]. Entrevistadora: Sandra Moura. João Pessoa. 1 arquivo .mp3 (30 min.).

7 REYNALDO, Carmélio. Entrevista. [jun. 2018]. Entrevistadora: Sandra Moura. João Pessoa. 1 arquivo .mp3 (60 min.).

8 NÓBREGA, Rubens José Barbosa da. Entrevista. [jun. 2018]. Entrevistadora: Sandra Moura. João Pessoa. 1 arquivo .mp3 (60 min.). 
Tribuna, na coluna Fidibeque, na análise dos periódicos paraibanos, a partir dos critérios jornalísticos e da deontologia da profissão (CORREIA NETO, 2018). Em pouco menos que um trimestre de atuação, os críticos decidiram encerrar as verificações, “após a direção do semanário sofrer pressão por parte de editores dos jornais sobre os quais escreviam", conforme Correia Neto (2018).

No Correio da Paraíba, a primeira fase dos ouvidores, de 1991 a 1993, é marcada pela produção dos relatórios internos, pela publicação da coluna (Re)Visão, pela boa convivência entre ombudsmans e editores e pela baixa interação com o leitor. A segunda fase, com Rubens Nóbrega, destaca-se pelo tom mais contundente da coluna, a permanência dos boletins, a participação e publicação dos comentários dos leitores no próprio jornal e o clima instável com os editores, com sinais de possível censura. O trabalho desenvolvido pelos jornalistas em $O$ Norte e A Tribuna inicia o movimento de crítica de mídia, que seria visto poucos anos depois no Correio da Paraíba, já na configuração de ombudsman.

\section{A autocrítica em $O$ Norte: a figura do pré-ombudsman}

O jornal $O$ Norte foi fundado em 7 de maio de 1908 pelos irmãos Oscar Soares e Orris Eugênio Soares, em João Pessoa, com a proposta de inovar no conteúdo das informações oferecidas ao público, com colunas diagramadas. Os seus primeiros cinquenta anos são marcados pelo fechamento e reabertura do jornal depois de várias crises políticas e econômicas (ARAÚJO, 1983). Foi um dos pioneiros na Paraíba a implementar a impressão off-set. A partir de 1954 passou a integrar os Diários Associados de Assis Chateaubriand, encerrando sua circulação em fevereiro de 2012.

Evandro da Nóbrega iniciou sua trajetória no jornal como redator e ocupou cargos como colunista, editorialista, secretário de redação até chegar a editor-geral. Entre os anos de 1970 e 1980, ele realizou estudos sobre imprensa, rádio e TV nos Estados Unidos, onde entrou em contato com diferentes conceitos de ombudsman.

Em entrevista, Evandro da Nóbrega (2019) contou que, quando retornava ao Brasil, costumava compartilhar suas descobertas e trocar ideias sobre o papel e a importância do ombudsman num órgão de imprensa - falado ou impresso - porém não cogitou sugerir a implantação dessa figura no jornal no qual atuava. Algo bem próximo desse sistema seria proposto pelo jornalista Wills Leal. Ele trabalhou como revisor de provas, noticiarista, colunista, crítico cinematográfico, entrevistador, chefe de 
reportagem, editor eventual e organizador de eventos no próprio O Norte. Wills Leal começou a atuar no periódico ingressando primeiro como revisor e, posteriormente, como colunista e articulista.

Dentro desse período, por uns dois anos, o jornalista, por iniciativa própria, passou a fazer a autocrítica do jornal, em acordo com a direção de $O$ Norte, na gestão de Marconi Góes. De acordo com o jornalista Evandro da Nóbrega, editor-geral no período em que as análises já eram realizadas, Wills Leal preparava os boletins em casa e não ganhava nenhum adicional pela tarefa. Segundo ele, pela manhã o jornalista lia $O$ Norte e os demais jornais locais e, em duas ou três laudas, enumerava as suas observações.

O "método willsiano" iniciava-se com a crítica das manchetes, seguido dos títulos principais, passando também por análises das notícias e reportagens mais importantes. Em cinco cópias, feitas em papel carbono, datilografava suas recomendações para aquele determinado dia ou edição do jornal. A tarefa era realizada de segunda-feira a sábado. A edição do domingo, sempre mais volumosa, era objeto de uma análise especial no dia seguinte, no qual tradicionalmente o jornal não circulava.

\footnotetext{
Wills Leal procurava analisar todas as queixas possíveis, fossem elas formuladas ou não pelos leitores. Isto é, o próprio Wills é quem 'levantava a lebre', por exemplo, quando a reportagem não fora devidamente aprofundada. Mas também elogiava as matérias boas e/ou excelentes divulgadas naquela edição em particular. Recomendava ações corretivas, quando era o caso. Chegava a 'repreender' nominalmente tal ou qual repórter, tal ou qual redator, tal ou qual colunista - e o assinalado não demonstrava contrariedade, porque sabia: a crítica do Wills não era de natureza pessoal, mas institucional. Não procurava atingir a vaidade de ninguém. E todo mundo conhecia o idealismo, a impessoalidade, a honestidade intelectual do autor das críticas, todas construtivas. Os alertas de Wills Leal dirigiam-se a todos, fossem o diretor-geral, o superintendente, o editor-geral, os editores setoriais, o secretário de redação, o chefe de reportagem e até o pessoal das oficinas (NÓBREGA, E., 2019).
}

De acordo com Evandro da Nóbrega, Wills Leal ia pessoalmente à sede do jornal, procurando conversar com os principais envolvidos, depois de entregar as cinco cópias de sua "análise" ao diretor-geral dos Diários Associados, ao superintendente do jornal $O$ Norte, ao editor-geral, ao secretário de redação e ao chefe de reportagem. As cópias dos boletins circulavam internamente. As críticas de Wills Leal não se dirigiam apenas a $O$ Norte, mas abrangiam também jornais como o Correio da Paraíba e $A$ União, além de semanários como $O$ Momento, com críticas ou elogios, quando, por exemplo, ocorresse de $O$ Norte ser "furado" por algum desses concorrentes. 
As intervenções eram bem recebidas pelo próprio editor-geral Evandro da Nóbrega. Entretanto, essa postura não era unanimidade e incomodava alguns repórteres. A publicação das críticas mesmo dentro da redação era uma raridade. Wellington Farias foi repórter no período em que Wills Leal redigia os boletins. "A gente sabia que ele fazia esse trabalho, algumas vezes a gente o via lendo a crítica ou ele entrando com o papel para entregar no jornal. Não havia uma exposição pública, era uma coisa absolutamente interna" (FARIAS, 2019) ${ }^{9}$.

Ao considerar as diretrizes formuladas pela Organization of News Ombudsmen and Standards Editors (ONO) - internacional que representa ombudsmans e editores de padrões em jornais, emissoras e redações digitais em todo o mundo - acredita Evandro da Nóbrega, Wills Leal, já naquela época, cumpria suas funções, mesmo sem ter conhecimento de tais normas. Desse modo, intuitivamente o crítico contribuiu para aperfeiçoar a equidade, a exatidão e a responsabilidade do jornal.

\section{A Tribuna: o jornalismo de oposição e os jornalistas críticos}

Diferente de $O$ Norte, no semanário A Tribuna a crítica de jornais recebeu o status de coluna na publicação intitulada Fidibeque ${ }^{10}$ - aportuguesamento do termo feedback -, assinada pelos jornalistas Alarico Correia Neto e Fernando Moura. No jornal, durante quatro edições, iniciada em agosto de 1989, os críticos fizeram uma avaliação geral da imprensa paraibana, um mês antes do ombudsman estrear e se popularizar com a Folha de S. Paulo, naquele mesmo ano.

Em A Tribuna, autointitulado um jornal de oposição, a coluna se situava no caderno Comunicação, constituído por pequenas notas, um artigo com comentários ou entrevistas, um quadro com o título de "Caixa Alta" ou "Caixa Baixa", - cuja localização variava conforme fossem feitas observações positivas sobre algum tema ou negativas, respectivamente -, e a seção "Corpo 8", com assuntos mais gerais como uma conversa de "pé de orelha" ou "à boca miúda". O campo de análise de Fernando Moura e Alarico Correia Neto incluía os jornais impressos, semanários, TVs, rádios, agências de publicidade e o empresariado, principalmente local, mas com algumas inserções nacionais (CORREIA NETO, 2018).

\footnotetext{
9 FARIAS, Wellington. Entrevista. [out. 2019]. Entrevistadora: Marcella Machado. João Pessoa. 1 arquivo .mp3 (10 min.).

10 Os jornalistas partiam da crença da "modernidade da adequação linguística de um termo gerado numa tecnologia avançada - a cibernética" -, que se impunha em todas as atividades produtivas do gênero humano (MOURA; CORREIA NETO, 1989).
} 
A primeira edição, que circulou entre 20 e 28 de agosto de 1989, trouxe no título um asterisco e ao lado um quadro no qual explicava os objetivos da nova produção. Segundo a nota, os jornalistas se basearam nos sentidos do termo feedback, a partir da definição constante no Dicionário de Comunicação, de Rabaça e Barbosa (2002). Na obra, ajudar "a fonte a apurar os resultados obtidos na transmissão de mensagens, em relação aos seus objetivos iniciais" e permitir ver, "como num espelho, em um enfoque crítico, a adequação ou a inadequação de ideias, sentimentos ou ações" (RABAÇA; BARBOSA, 2002, p. 303) eram algumas das propostas expressas.

Entre os objetivos de Fidibeque estava avaliar e auferir o quanto as mensagens emitidas, tanto pelo jornal A Tribuna, quanto pelas demais mídias, encontravam as respostas pretendidas dos receptores, assim como retornar as fontes a opinião apurada dos receptores com relação às mensagens, ou seja, informar os veículos de comunicação o que pensava o público (MOURA; CORREIA NETO, 1989). A finalidade desse trabalho, de acordo com Fernando Moura e Alarico Correia Neto, era de que as observações, com críticas positivas ou negativas, contribuíssem para melhorar o nível das mídias locais, como proposto pela sistemática do ombudsman.

$\mathrm{Na}$ coluna, Alarico Correia Neto e Fernando Moura analisavam o perfil e as características de programas de televisão e de rádio, as produções, o comportamento e aspectos do currículo profissional de jornalistas, atividades dos cursos de Comunicação e de entidades de classe e sindicais da categoria, observações sobre o mercado de trabalho na área, demissões e contratações de jornalistas, as condições estruturais dos jornais, a linha editorial e tópicos referentes a questões gramaticais e técnicas nos textos jornalísticos. Nas publicações, os comentários são direcionados ora para um grupo específico, ora de forma mais generalista, como nos exemplos a seguir:

Révizão - Enquanto a informatização não chega às redações locais, os jornais deveriam investir mais em seus setores de revisão. Erros gramaticais, de acentuação e pontuação já são regra. A exceção fica por conta de $\boldsymbol{A}$ Carta.

Em tempo: revisar um texto nem sempre é só corrigir palavras. Garantir que o sentido dado pelo redator seja mantido também, teoricamente, é atribuição da Revisão. Nesse caso, o título "revisão" permanece (MOURA; CORREIA NETO, 1989).

Gramatical - Que os jornais paraibanos insistam em desconhecer a existência do trema é até compreensível. Afinal, dentro da tese separatista vai incluída a adoção de nova língua com regras gramaticais específicas da região.

Já o paulistano Folha da Tarde em manchete de primeira página (14.08.89), vomitar seqüestrador sem o trema, é imperdoável (MOURA; CORREIA 
NETO, 1989).

Choque - Um artigo que destoava da atual linha editorial do jornal $\boldsymbol{O}$ Momento, resultando em sua suspensão, foi o principal motivo do afastamento do analista político e presidente eleito da API, Agnaldo Almeida, dos quadros da empresa. Discordando, Almeida agradeceu e saiu.

Até quando os poderes públicos influenciarão e decidirão sobre o material jornalístico paraibano é a pergunta que tem prevalecido no meio. (MOURA; CORREIA NETO, 1989).

Magia - O Norte é, possivelmente, o único jornal do mundo que é elaborado sem a contribuição da Redação. Só tem Diretores. Quem diz é o expediente do veículo (MOURA; CORREIA NETO, 1989) ${ }^{11}$.

A quase ausência da autocrítica em A Tribuna chama atenção quando comparado com o papel que o ombudsman viria a ter com a Folha de S. Paulo. As menções diziam respeito, em sua maioria, às práticas dos jornais $\mathrm{O}$ Norte, A União, Correio da Paraíba e Jornal da Paraíba, de semanários como $O$ Momento e $O$ Combate do que propriamente sobre si próprio. Como a coluna só estava em seu início e pelo ineditismo da iniciativa, é provável que isso tenha se dado por conta desses fatores.

Na leitura de Fidibeque, é possível perceber que havia por parte dos jornalistas uma tentativa de explicar a função daquele espaço. Ainda em sua segunda edição, os jornalistas trouxeram uma definição de media-criticism, como um "gênero de crítica que analisa e opina sobre jornais, revistas, emissoras de rádio e televisão, procurando contribuir para o aprimoramento desses produtos", apontado como objetivo de Fidibeque, feito "sem apologias ou ataques pessoais" (MOURA; CORREIA NETO, 1989). Fernando Moura considera que esse trabalho foi o primeiro a ter uma abordagem autocrítica em relação à imprensa, embora o fato de não ter havido uma contratação específica para que atuassem como ombudsman não os permitissem serem classificados como tal.

Era uma coluna de variedades da mídia, de uma forma geral. A gente abordava a análise dos jornais, das revistas, das rádios, da televisão que ainda estava iniciando e dos bastidores da imprensa. A gente circulava muito. Era um período que os jornalistas se encontravam muito nos restaurantes, nos bares, nas coletivas, na Associação Paraibana de Imprensa (API) e circulava muita informação. Então, o que nos cabia, a mim e a Alarico, era fazer essa triagem, ter uma abordagem analítica, com um viés em alguns momentos até de acidez, outros de sátira, de humor, uma coisa mais leve e também coisas pesadas. Tanto é que quem leu ou gostou muito ou detestou muito, não teve um meio termo (MOURA, 2018).

\footnotetext{
11 Nos documentos do semanário A Tribuna a que tivemos acesso para este trabalho, só localizamos ano de publicação e data da semana em que a edição circulou. Daí aparecerem aqui somente sobrenomes dos autores e ano da publicação.
} 
Nela havia ainda a participação e a influência do público. Em sua terceira edição, os jornalistas destacaram que a boa aceitação da coluna vinha dos profissionais, professores e alunos de Comunicação, com o recebimento de telefonemas e correspondências, principalmente de pessoas preocupadas com o destino do jornal $A$ União. Na ocasião, Alarico Correia Neto e Fernando Moura iniciaram uma campanha em favor da sobrevivência do periódico, com opiniões de profissionais, como Carlos César Muniz (então presidente do Sindicato dos Jornalistas da Paraíba), Walter Santos (editor de $O$ Momento), Derval Golzio (na época, professor do Departamento de Comunicação da UEPB) e José Vieira Neto (ex-produtor de notícias da TV Cabo Branco). Reflexões sobre a função da coluna estariam presentes até a quarta e última edição, na qual os jornalistas destacavam que Fidibeque motivara discussões conceituais entre os seus responsáveis e demais profissionais da área.

A vida útil da crítica de mídia em A Tribuna também foi curta, durou quatro edições: a primeira, de 20 a 26 de agosto de 1989; a segunda, de 27 de agosto a 2 de setembro; a terceira, de 3 a 9 de setembro; e a quarta, de 10 a 16 de setembro.

Alarico Correia Neto lembra que a coluna desagradava a organizações empresariais da imprensa paraibana. E um artigo escrito por Fernando Moura sobre o jornal $O$ Norte, o mesmo periódico que décadas anteriores ensaiou a figura do ombudsman no jornalismo paraibano, foi o estopim. A crítica do jornalista, como costumava ocorrer, desagradou os envolvidos e o editor, e assim os críticos tiveram que encerrar a coluna. Segundo relata Moura (2018), a análise em questão envolvia, além de $O$ Norte, empresários de outros veículos de comunicação.

Moura (2018) avalia que a exposição sofrida pelos donos das empresas no semanário tenha contribuído para o fim da coluna: "Os que detestaram saíram vitoriosos porque a coluna só durou quatro edições, quatro finais de semana, foram quatro páginas inteiras". De acordo com Moura, Fidibeque tinha um caráter pedagógico, político, cultural e histórico. A coluna existiu durante um forte período de movimentação política, como as campanhas para eleição da Assembleia Constituinte e para os governos municipal e estadual. O cenário local e nacional, segundo o jornalista, refletia nas abordagens dos veículos de mídia paraibanos. 


\section{O Correio da Paraíba e a figura do ombudsman}

No jornal Correio da Paraíba, fundado em 5 de agosto de 1953, por Teotônio Neto, o surgimento da figura do ombudsman deu-se inspirado no modelo da Folha de S. Paulo (NÓBREGA, R., 2018). O contexto político local, a linha editorial do jornal, a implementação da informatização e a alta rotatividade de editores-gerais do jornal são alguns aspectos que devem ser considerados para compreender as experiências do ombudsman no Correio da Paraíba.

A primeira fase do ombudsman no jornal ocorreu de 1991 a 1993, sob a editoria do jornalista Rubens Nóbrega, que permaneceu no periódico até 1992. Ele já havia sido editor do jornal de 1981 a 1989 e retornou à empresa e ao cargo em 1991, com a proposta de uma reforma na estrutura editorial, intitulada de "Projeto Líder". Entre outros pontos, a iniciativa do jornalista previa a vigência da figura do ombudsman, sugestão também reivindicada pelo superintendente do Correio da Paraíba, Alexandre Jubert (ROSAS, 2015).

Para ocupar o lugar de ombudsman, Rubens Nóbrega convidou os professores do curso de Comunicação Social da Universidade Federal da Paraíba (UFPB), Alarico Correia Neto e Carmélio Reynaldo. Intitulada de (Re)Visão, com desenho em dégradé nas letras feito por Mike Deodato, a coluna era semanal. Mesmo com a nova atividade e o convênio firmado, os docentes não tiveram dispensa de carga horária na universidade. A experiência de Alarico Correia Neto como ombudsman durou um ano e a de Carmélio Reynaldo, dois. Durante esse período, produziram relatórios internos inicialmente diários e em seguida semanais, até a sua extinção - e a coluna (Re)Visão, publicada aos domingos. A parte mais técnica das análises era responsabilidade de Alarico Correia Neto, já os aspectos políticos e ideológicos ficavam por conta de Carmélio Reynaldo.

O assunto principal a ser analisado na coluna dominical era escolhido pelos próprios ombudsmans. Segundo Reynaldo (2018), os dois observavam o assunto considerado o mais importante da semana, podendo ser o "erro" ou o "acerto" do jornal. Entre as críticas positivas realizadas pelos ouvidores está uma matéria sobre o primeiro sequestro ocorrido em João Pessoa, o caso das turmalinas azuis e uma série de reportagens sobre o tráfico de bebês para a Europa. Além da análise principal, os ombudsmans também faziam notas pequenas chamando atenção para outros aspectos das edições (REYNALDO, 2018). 
Em meio à primeira experiência dos ombudsmans, o editor Rubens Nóbrega foi demitido do jornal após publicar um artigo intitulado "O retiro do poder", no qual apresentava os gastos da estadia da equipe de governo de Ronaldo Cunha Lima (19911994) em um resort de Alagoas, no Carnaval. Nesse período, a Paraíba vivia uma epidemia de cólera e nenhuma autoridade estava no estado para tratar do assunto com a imprensa. Rubens Nóbrega foi afastado do Correio da Paraíba e os jornalistas Walter Santos e Giovanni Meireles assumiram os cargos de editor e editor-adjunto, respectivamente. $\mathrm{O}$ mandato do primeiro durou apenas seis meses e o segundo ficaria por quatro anos como editor-geral. A demissão do idealizador do ombudsman foi assunto de algumas edições da coluna (Re)Visão (ROSAS, 2015).

Ainda nessa fase, segundo Meireles (1994), a direção do Correio da Paraíba havia iniciado o processo de informatização da redação. Além da dificuldade de adaptação da maioria dos jornalistas aos computadores, houve uma redução de custos de produção industrial e do quadro de pessoas, de sessenta para quarenta e cinco funcionários como forma de contenção de despesas. Foram demitidos pela empresa jornalistas, revisores, digitadores, paginadores, e ainda encolhidas e excluídas páginas dos cadernos, como os de Cultura, por exemplo. Com a mudança de governo, o jornal, com forte alinhamento político, deixou de fazer oposição para assumir uma postura favorável a nova gestão (MEIRELES, 1994).

A segunda fase de ombudsman iniciou-se em 1995, já sob a editoria de Giovanni Meireles, que assumiu o posto em 1992 com a saída de Walter Santos, que, por sua vez, havia sucedido Rubens Nóbrega. A coluna deixa de chamar-se (Re)Visão e ganha o próprio título de Ombudsman. Nesse período, Rubens Nóbrega retorna ao jornal, dessa vez como ombudsman, e sua coluna é marcada por uma postura mais contundente do que a seguida por Carmélio Reynaldo e Alarico Correia Neto. O artigo de estreia, publicado em 23 de abril de 1995, intitulado de “É o jornal do PMDB?", refletia a postura que seria adotada pelo "fiscal do leitor". Além da coluna, o jornalista produzia um boletim interno. $\mathrm{O}$ acordo contratual, formulado pelo próprio ombudsman especificamente para a função e aceito pela direção do Correio da Paraíba, firmava que a coluna duraria um ano, podendo ser renovado por mais um mandato e também com multa rescisória.

Assim como nas experiências de $O$ Norte e A Tribuna, os ombudsmans esbarravam na dificuldade de os jornalistas receberem críticas, como observa Alarico 
Correia Neto sobre a recepção por parte desses profissionais. Ele destaca que "notou que o dissabor era mais entre os jornalistas. Comentava até alguns deslizes de concordância, a parte gramatical e isso chamava atenção. O pessoal ficava muito chateado. Fizeram até charge com a gente" (CORREIA NETO, 2018). Com relação a postura dos dirigentes, a situação era mais tranquila, como destaca Carmélio Reynaldo, já que o tom adotado não era tão contundente quanto o de Rubens Nóbrega (REYNALDO, 2018).

O papel dos ombudsmans, somado às atividades acadêmicas, mais a resistência na redação, encurtaram a primeira fase de experiência dos críticos no Correio da Paraíba. Embora não trabalhassem no mesmo ambiente que os jornalistas e com uma editoria favorável ao trabalho dos ouvidores - inicialmente capitaneada por Rubens Nóbrega, em seguida por Walter Santos, e Giovanni Meireles - a presença dos ombudsmans incomodava. Na segunda experiência, já com Rubens Nóbrega, em 1995, além de os jornalistas não receberem bem os boletins internos, o ombudsman também enfrentava problemas com a direção do jornal Correio da Paraíba. "Não havia a cultura de lidar com a crítica nessas situações. Expor o jornal, se expor, criticar o perfil, a condução editorial e, realmente, eles não aceitaram muito bem isso" (NÓBREGA, R., 2018).

Meireles (2019) ${ }^{12}$, que editou o jornal quando Rubens Nóbrega era ombudsman, relembra o clima da época e um dos episódios que contribuíram para o fim do ouvidor no Correio da Paraíba. Ele aponta que além dos problemas de adaptação com a informatização, a equipe de redação reduzida e a linha editorial difícil, ainda tinha que lidar com as críticas ácidas de Rubens Nóbrega sobre o jornal.

Na época de Giovanni Meireles, na editoria do jornal, uma das colunas do ombudsman deveria ter sido publicada no dia 23 de julho de 1995, mas só foi veiculada no dia 26 do mesmo mês. Coincidentemente, o título da coluna em questão era "Censura no Correio". Entre os conteúdos abordados estava um documento interno do Correio da Paraíba de aviso-advertência endereçado à Redação, considerado, por Rubens Nóbrega, uma forma de censura. Nessa edição do jornal, ao lado da coluna Ombudsman, foi publicada uma nota oficial do jornal, na qual a direção rebatia o

12 MEIRELES, Giovanni Emmanuel Silva. Entrevista. [out. 2019]. Entrevistadora: Marcella Machado. João Pessoa. 1 arquivo .mp3 (1h12min.). 
conteúdo analisado pelo ombudsman. Meireles (2019) explicou os bastidores desse episódio.

\begin{abstract}
A coluna de Rubens Nóbrega, na verdade, foi censurada pela metade. A outra metade, a parte em que ele falava de outras coisas de conteúdo, de erro de abordagem, foi publicada normalmente. No lugar da outra metade, saiu um anúncio. A coluna não foi cortada, inteira, $100 \%$. Eu cortei a metade a pedido dos colegas de redação. Criou-se um mal-estar. Rubens, como ombudsman, e eu, como editor, à época, sentamos com Alexandre Jubert, o superintendente do jornal, e com o próprio José Fernandes Neto, fundador do Correio da Paraíba, junto com Roberto Cavalcanti, o diretor, e chegamos a um acordo. José Fernandes disse: 'Giovanni escreve a parte dele. A parte de Rubens, que não foi publicada, vai ser publicada e eu (Zé Fernandes Neto), como representante da diretoria, vou escrever um artigo posicionando a empresa. Então, essa página minha foi, na verdade, uma parte minha e da diretoria (MEIRELES, 2019).
\end{abstract}

Ainda assim, Rubens Nóbrega permaneceu como ombudsman no Correio da Paraíba até 1996, quando a editoria geral do jornal já era comandada por Lena Guimarães, que sucedeu Giovanni Meireles.

Mesmo com o incômodo dos jornalistas com as críticas, os ombudsmans acreditam que os boletins, relatórios e a coluna trouxeram contribuições. Rubens Nóbrega, editor na época que Alarico Correia Neto e Carmélio Reynaldo atuaram como críticos, define o trabalho dos professores como uma aula semanal para os profissionais da redação. Como ombudsman, as interferências de Rubens Nóbrega diziam respeito aos aspectos ligados as técnicas do jornalismo; já no caso dos professores, a abordagem era mais ampla.

\begin{abstract}
Uma das coisas que me lembro bem, foi até o título da minha coluna com 'Amigo não mata amigo', porque era danado para dizer, o 'cara estava bebendo com o amigo e matou'. Foi uma das coisas que eu me lembro bem, o jornal parou de colocar isso nas matérias. Teve alguma coisa assim com relação a preconceito, machismo, que a gente foi chamando atenção e nesse caso eu tive uma interlocução muito boa com Lena Guimarães. Ela, às vezes era quem me chamava atenção, 'olha Carmélio, saiu isso, saiu aquilo'. Eu ia lá e criticava. O jornal começou a ter mais cuidado. Eu acho que no final, quando terminou, tinha melhorado bastante a qualidade, o cuidado também com a qualidade do texto, coisas desse tipo (REYNALDO, 2018).
\end{abstract}

Quanto ao público, a primeira fase da experiência do ombudsman no Correio da Paraíba é marcada pelo baixo engajamento dos leitores com a coluna, destacando-se interferências pontuais. De acordo com Reynaldo (2018), não havia uma estratégia mais efetiva de acesso do público aos críticos, além do contato disponível na própria coluna publicada aos domingos. Segundo ele, nos dois anos em que atuou, contabiliza 
apenas o recebimento de dez cartas, nas quais a maior parte trazia críticas ao ombudsman. De acordo com o professor, o retorno vinha de pessoas próximas. Lembra, também, que o jornal retirou, por um tempo, o espaço da Carta do Leitor que o periódico mantinha. "Atender ao leitor" é uma das obrigações do ombudsman. Como não havia, de fato, essa interação, as decisões sobre a coluna eram tomadas em conjunto entre os críticos e com o pouco feedback recebido (REYNALDO, 2018).

Na segunda experiência de ombudsman no Correio da Paraíba, com Rubens Nóbrega, a participação dos leitores foi maior, de acordo com o relato do jornalista. $\mathrm{O}$ crítico chegava a publicar o conteúdo de cartas enviadas para a coluna.

\begin{abstract}
$\mathrm{Na}$ época, recebia muitas cartas, sugestões. Uma me recordo bem, foi a de um cidadão que se identificou como El Sid [...]. Era realmente um intelectual que tinha, a gente sentia no texto dele, uma densidade intelectual fantástica. Ele escrevia muito bem e batia na canela, no fígado, bem certinho, no ponto. Comecei a publicar, dentro da coluna Ombudsman, colaborações desse tipo, nesse nível e eram muito boas. E outros caras, até a própria plêiade de intelectuais, começaram a também querer colaborar, embora alguns não tivessem o mesmo nível de El Sid (NÓBREGA, R., 2018).
\end{abstract}

Ao observar a prática do ombudsman no Correio da Paraíba, Carmélio Reynaldo acredita que o trabalho desenvolvido se assemelhava mais a um observatório de mídia, do que propriamente à crítica de mídia. De acordo com o professor, "você faz, na verdade, um papel de amortecer as relações entre o público e a redação. Dá a impressão para o público que você está criticando, mas nem sempre a crítica é tão contundente" (REYNALDO, 2018). Para Nóbrega (2018) e Meireles (2019), a figura do ombudsman era vista mais como marketing para o jornal do que propriamente como um ganho para o leitor.

\title{
Considerações finais
}

Este artigo buscou relatar as atividades de crítica dos meios de comunicação no jornalismo paraibano a partir da experiência de três jornais locais. Em diferentes períodos e contextos, esses cinco jornalistas realizaram a autocrítica de periódicos nos quais trabalhavam ou para os quais foram requisitados. Sobre eles escreviam análises que circulavam de forma interna por meio de ofícios e boletins entre jornalistas e a direção, assim como em colunas nos jornais que adotaram a prática do ombudsman, mesmo quando essa denominação não havia se popularizado na imprensa brasileira.

Oficialmente, é a experiência do Correio da Paraíba - com Alarico Correia 
Neto, Carmélio Reynaldo e Rubens Nóbrega - que mais se aproxima das definições de ombudsman da Organização Mundial de Ombudsman de Imprensa (1982) e da experiência de Caio Túlio Costa (2006) na Folha de S. Paulo. No entanto, não podemos desconsiderar o trabalho inicial exercido pelo jornalista Wills Leal, em $O$ Norte, e de Fernando Moura e Alarico Correia Neto, em A Tribuna.

No contexto geral, embora atuando em períodos diferentes, há em comum na iniciativa desses profissionais (Wills Leal, Fernando Moura, Alarico Correia Neto, Carmélio Reynaldo e Rubens Nóbrega) a contribuição para a qualidade do jornalismo, o aperfeiçoamento da mídia paraibana e o desenvolvimento das suas relações com a sociedade.

Após essas experiências de crítica dos meios de comunicação na Paraíba, não há registros de implementação da figura do ombudsman em outros veículos de mídia no estado. O que existe são esporádicos artigos que debatem a imprensa paraibana em situações pontuais em colunas em jornais impressos ou em sites e blogs.

\section{Referências}

ARAÚJO, Fátima. História e ideologia da imprensa na Paraíba. João Pessoa: Editora A União: 1983.

CHRISTOFOLETTI, Rogério (org.). Vitrine e vidraça: crítica de mídia e qualidade no jornalismo. Covilhã: UBI/LabCom Books, 2010.

COSTA, Caio Túlio. Ombudsman: o relógio de Pascoal. São Paulo: Geração Editorial, 2006.

GIANGRANDE, Vera; FIGUEIREDO, José Carlos. O cliente tem mais do que razão: a importância do ombudsman para a eficácia empresarial. 2.ed. São Paulo: Editora Gente, 1997.

MANUAL DE REDAÇÃO. Folha de S. Paulo. 16. ed. São Paulo: PubliFolha, 2010.

MEIRELES, Giovanni Emmanuel Silva. Os focas digitais: jornalistas e informática nas redações paraibanas no início dos anos 90. 1994. Trabalho de Conclusão de Curso (Bacharelado em Comunicação Social) - Universidade Federal da Paraíba, João Pessoa, 1994.

MENDES, Jairo Farias. O ombudsman e o leitor. Belo Horizonte: Editora O Lutador, 2002.

MESQUITA, Mário. O jornalismo em análise: a coluna do Provedor dos Leitores em análise. Coimbra: Minerva, 1998. 
MOURA, Fernando; CORREIA NETO, Alarico. Fidibeque. A Tribuna, João Pessoa, 20-28 ago. 1989. Caderno Comunicação.

MOURA, Fernando; CORREIA NETO, Alarico. Fidibeque. A Tribuna, João Pessoa, 27 ago. 1 set. 1989. Caderno Comunicação.

MOURA, Fernando; CORREIA NETO, Alarico. Fidibeque. A Tribuna, João Pessoa, 3-9 set. 1989. Caderno Comunicação.

MOURA, Fernando; CORREIA NETO, Alarico. Fidibeque. A Tribuna, João Pessoa, 10-16 out. 1989. Caderno Comunicação.

RABAÇA, Carlos Alberto; BARBOSA, Gustavo Guimarães. Dicionário de Comunicação. 2. ed. Rio de Janeiro: Elsevier, 2002.

ROSAS, Juliana Amorim. Os cães ladram, a caravana passa e ao menos ao leitor se deve reverência: o pioneirismo regional do ombudsman paraibano entre críticas, estratégias e conflitos de ethos. 2015. Dissertação (Programa de Pós-Graduação em Comunicação) - Setor de Artes, Comunicação e Design, Universidade Federal do Paraná, Curitiba, 2015. Disponível: https://acervodigital.ufpr.br/handle/1884/48454. Acesso em: 10 de jul. 2020.

Submetido em: 04.12.2019

Aprovado em: 25.05.2020 